\title{
ORIGEM E TRANSFORMAÇÃO DOS NÚCLEOS URBANOS DAS CIDADES DE PIQUEROBI E PRESIDENTE VENCESLAU
}

\author{
Nathália Sousa de Araújo, Arlete Maria Francisco \\ Universidade Estadual Paulista - UNESP, Presidente Prudente, SP. E-mail: sousanahh@gmail.com \\ Órgão de fomento: Pibic/Reitoria
}

\begin{abstract}
RESUMO
O transporte ferroviário, até o final do século XX, desempenhou papel importante como indutor do desenvolvimento econômico do país e do processo de urbanização de cidades por onde os trilho passavam. Na região da Alta Sorocabana, a implantação da Estrada de Ferro Sorocabana deu origem aos núcleos urbanos, a partir das suas estações, e o traçado urbano em formato de tabuleiro de xadrez, um elemento morfológico comum entre elas, estes núcleos configuraram uma paisagem cultural significativa. Partindo do estudo de duas destas cidades, Piquerobi e Presidente Venceslau, que apresentam características comuns em sua formação urbana, buscou-se investigar a origem dos núcleos originais e a partir da sistematização das informações tentou-se responder algumas questões: quais os princípios formais orientaram os seus traçados? Quais as semelhanças e diferenças entre o traçado e a configuração dos elementos morfológicos entre as duas cidades? E quais as suas transformações ao longo do tempo?
\end{abstract}

Palavras-chave: Desenho urbano, Alta Sorocaba, Origem dos Núcleos, Piquerobi, Presidente Venceslau

\section{ORIGIN AND TRANSFORMATION OF URBAN CENTERS OF PIQUEROBI AND PRESIDENTE VENCESLAU}

\begin{abstract}
Rail transport by the end of the twentieth century, played an important role as a promoter of economic development of the country and the cities urbanization process where the track went. In the region of Alta Sorocabana, the implementation of Sorocabana Railway gave rise to urban centers, from their stations, and urban layout in checkerboard format, a common morphological element between them, these cores configured a significant cultural landscape. From the study of two of these cities, Piquerobi and Presidente Venceslau, that have common characteristics in its urban development, we sought to investigate the origin of the original nucleus and from the systematization of information we tried to answer some questions: what are the formal principles guided your strokes? What are the similarities and differences between the layout and configuration of morphological elements between the two cities? And what their changes over time?
\end{abstract}

Keywords: Urban Design, Alta Sorocabana, Origin of Cores, Piquerobi, Presidente Venceslau 


\section{INTRODUÇÃO}

O transporte ferroviário teve papel desbravador para além das áreas litorâneas, possibilitando avançar por regiões despovoadas e inexploradas. Assim, onde os trilhos da locomotiva alcançavam, formavam frentes colonizadoras, geradoras de riquezas, possibilitando o escoamento da produção e a acumulação do capital. No estado de São Paulo, a ferrovia chegou na década de 1860, sendo a São Paulo Railway a primeira a operar, ligando Santos a Capital. A produção de café que estava crescendo e se expandindo para o interior do estado fez crescer a demanda por transporte para escoá-la. Nesse contexto, surgiu outras companhias ferroviárias, entre elas a Estrada de Ferro Sorocabana (EFS), fundada em 1870, servindo como linha de penetração para a ocupação do Oeste Paulista (FRANCISCO, 2015).

A Alta Sorocabana, região compreendida entre os Rio do Peixe, Paranapanema e Paraná, até segunda metade do século XIX, aparecia nos mapas como "área despovoada". Os primeiros a desbravarem a região foram os mineiros que ali encontraram a oportunidade que as reservas auríferas não forneciam mais. Os mineiros abriram as primeiras picadas na mata, expulsando os índios e criando as condições para o povoamento da região, primeiramente, com a estrada boiadeira que permitiu o transporte de produção, atraindo agricultores, fazendeiros, aventureiros e grileiros. A segunda onda pioneira veio com a ferrovia, que permitiu a inúmeras companhias colonizadoras investir no retalhamento de grandes glebas (MONBEIG, 1984).

Abreu (1972) aponta que a ferrovia representou um meio de transporte rápido, seguro e barato para a produção cafeeira e também serviu para que os negociantes e compradores de terras conhecessem a região, o que favoreceu a penetração para o interior, a implantação dos loteamentos e a sua ocupação.

De acordo com Monbeig (1982), na Alta Sorocabana, a partir de Assis, houve um perfeito sincronismo entre expansão cafeeira e ferroviária, quando não uma precedência. Assim, se as estações surgiram como pontos de apoio ao escoamento da produção e à alimentação das máquinas, os núcleos urbanos surgiram como pontos de apoio para a exploração econômica da região.

O núcleo original desta e das outras cidades, juntamente com seus edifícios, praças e esplanadas, constituem testemunhos significativos da arquitetura ferroviária do estado e da história das cidades brasileiras. Esta pesquisa se propôs a realizar o estudo de duas destas cidades que surgiram a partir da expansão da Estrada de Ferro Sorocabana na Alta Sorocabana as quais apresentam características comuns em seu processo de formação urbana: Piquerobi e Presidente Venceslau.

\section{OBJETIVOS}

Investigar a origem dos núcleos urbanos dos municípios e realizar a sua análise morfológica a fim de contribuir para a identificação de uma tipologia de desenho urbano na Alta Sorocabana. Como objetivos específicos, identificar as transformações ocorridas nos traçados urbanos e identificar os atores da produção do núcleo urbano que originou as cidades.

\section{METODOLOGIA}

Esta pesquisa se desenvolveu a partir do método de análise morfológica utilizando os autores: LAMAS (1999) e PANERAI (2006). Para tanto, foram utilizados bibliografia disponível acerca das cidades em estudo e da ocupação do Oeste Paulista; além da documentação disponível no Arquivo Público do Estado de São Paulo, no Instituto Geográfico e Cartográfico e no Escritório da Inventariança da Rede Ferroviária Federal SA em São Paulo e trabalho de campo. 


\section{RESULTADOS}

As cidades de estudo Piquerobi e Presidente Venceslau tiveram seu ponto de origem a partir das estações ferroviárias, cujas esplanadas possuíam em sua organização espacial a estação, os galpões e as casas dos ferroviários (figuras 1 e 2).
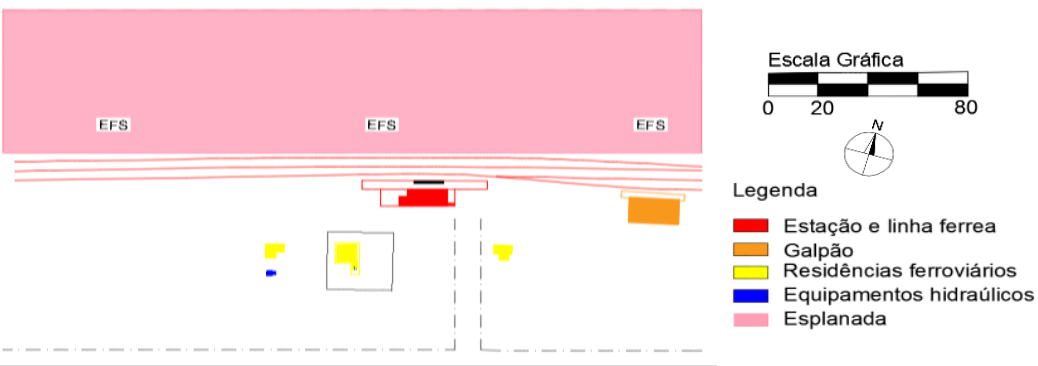

Figura 01. Esplanada de Piquerobi

Fonte: Rede Ferroviária Federal SA, redesenhado pela autora

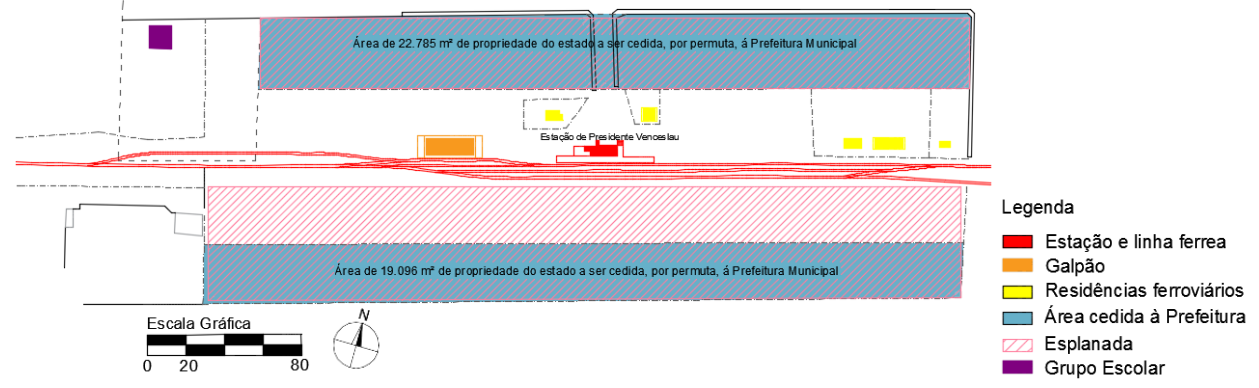

Figura 02. Esplanada de Presidente Venceslau

Fonte: Rede Ferroviária Federal SA, redesenhado pela autora

O traçado original das cidades seguiram o padrão tabuleiro de xadrez, ou seja, traçado ortogonal com modelos de quadras medido 88 metros $\times 88$ metros, ruas medido em torno de 13,20 metros. Ambas as cidades possuíram ocupação dos dois lados da ferrovia, contudo, apenas Presidente Venceslau foi planejada para tal, (figuras 3 e 4). Esses fatos são reforçados pelos registros de aerofotografias do Instituto Geográfico e Cartográfico de 1939/40, que demostram a maior ocupação de Piquerobi do lado oposto da ferrovia, no seu primeiro núcleo urbano; e em Presidente Venceslau uma ocupação mais constante na cidade (figura 5).

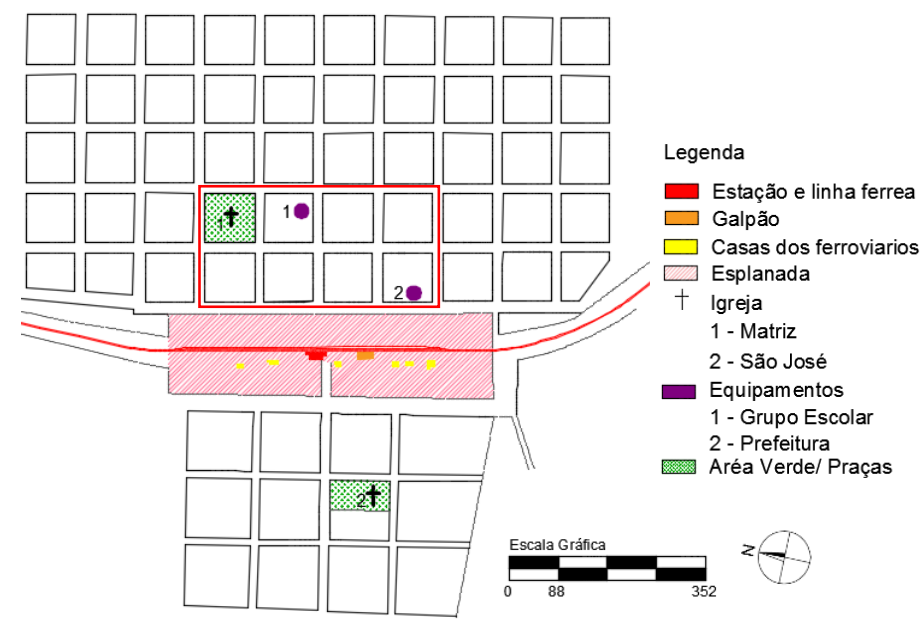

Figura 3. Núcleo Original de Piquerobi

Fonte: Arquivo Público do Estado de São Paulo e trabalho de campo, desenhado pela autora 


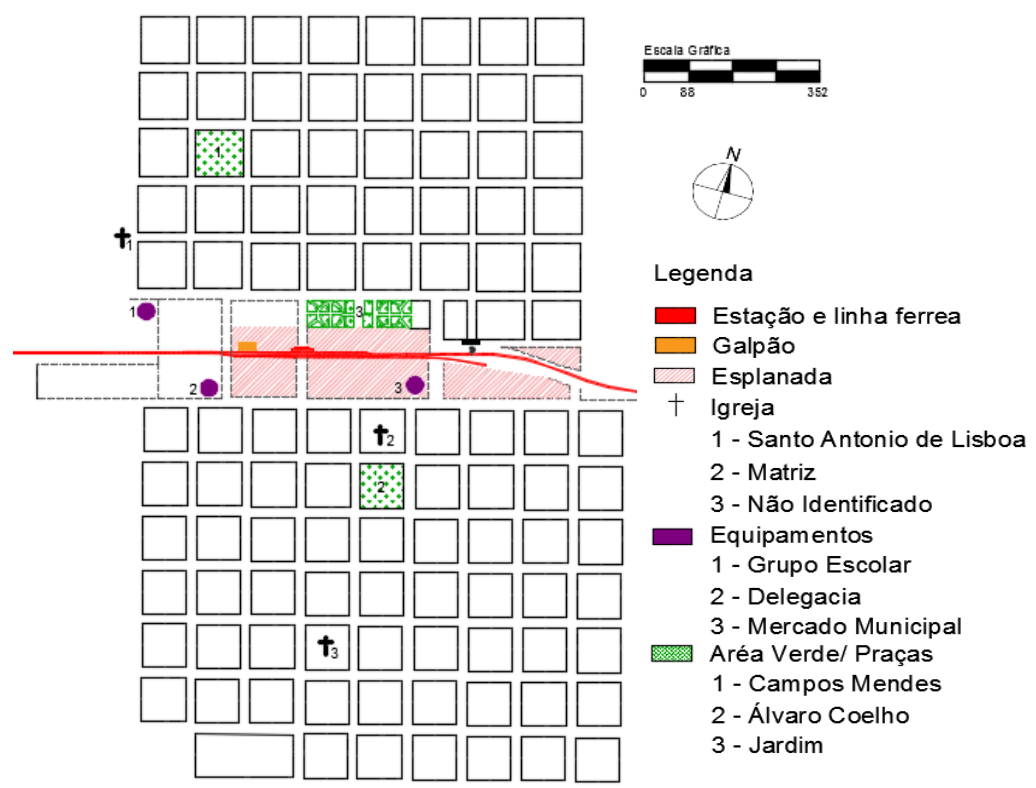

Figura 04. Núcleo Original de Presidente Venceslau

Fonte: Arquivo Público do Estado de São Paulo e trabalho de campo, desenhado pela autora

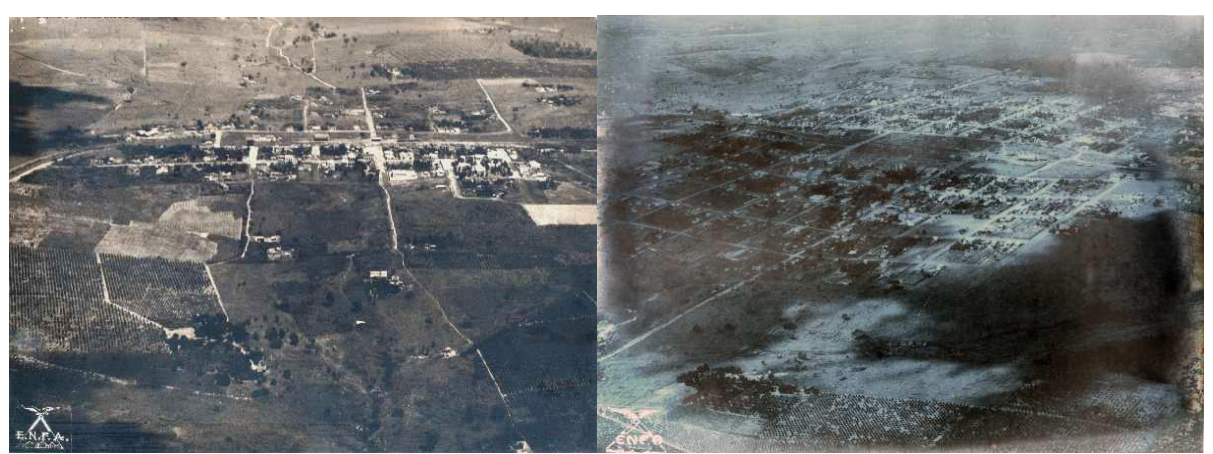

Figura 05. Aerofotografias de Piquerobi e Presidente Venceslau, respectivamente Fonte: Instituto Geográfico e Cartográfico

O crescimento das cidades são diferenciados: Piquerobi não sofreu grandes transformações em seu traçado (figura 6), expandindo muito pouco do traçado original, principalmente devido à pouca evolução populacional da cidade. Presidente Venceslau teve uma expansão significativa, mas, não necessariamente, seguiu a continuidade do traçado xadrez (figura 7), mesmo esse sendo bem marcante na cidade. 


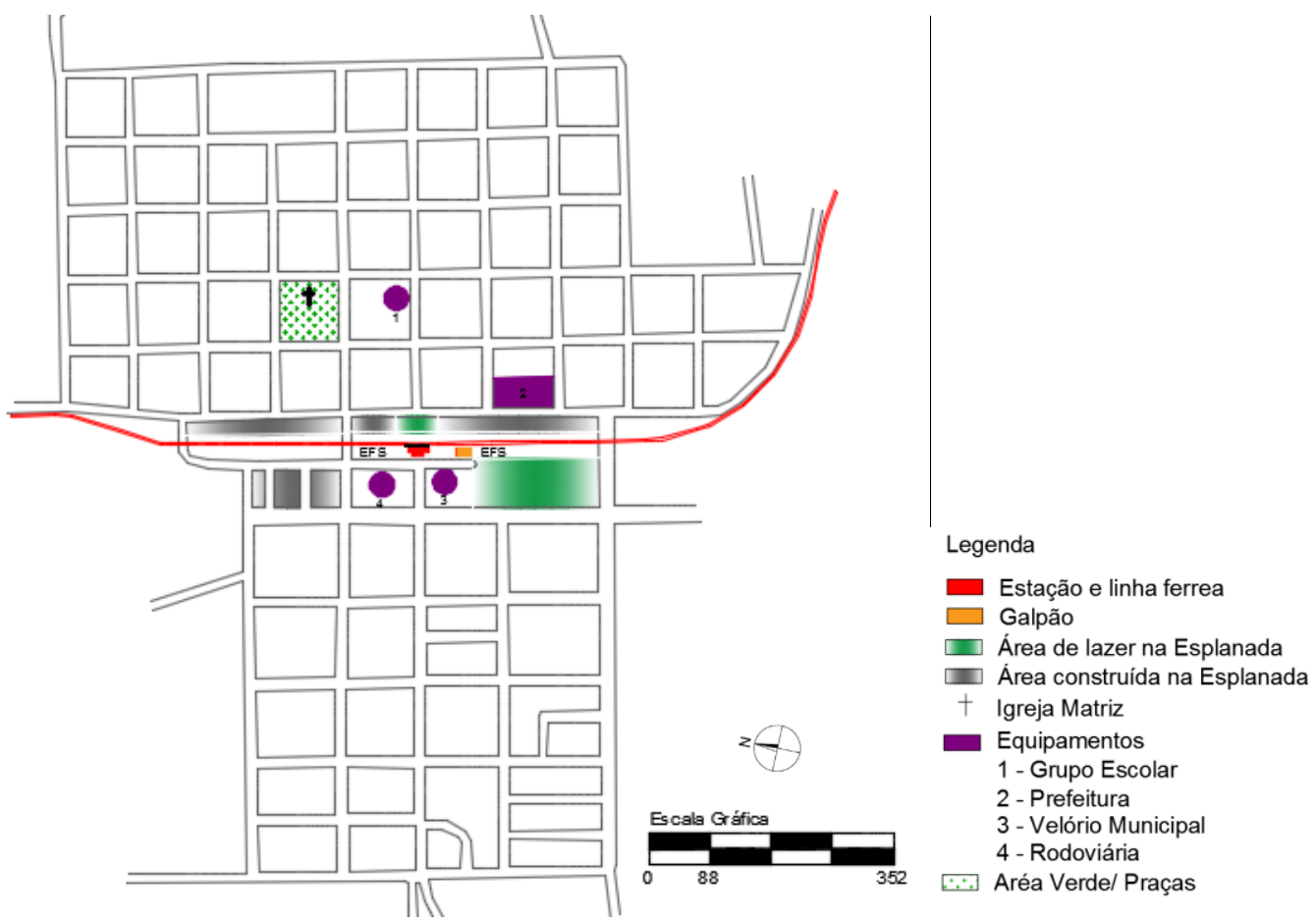

Figura 06. Mapa atual de Piquerobi

Fonte: Google Maps e trabalho de campo, desenhado pela autora.

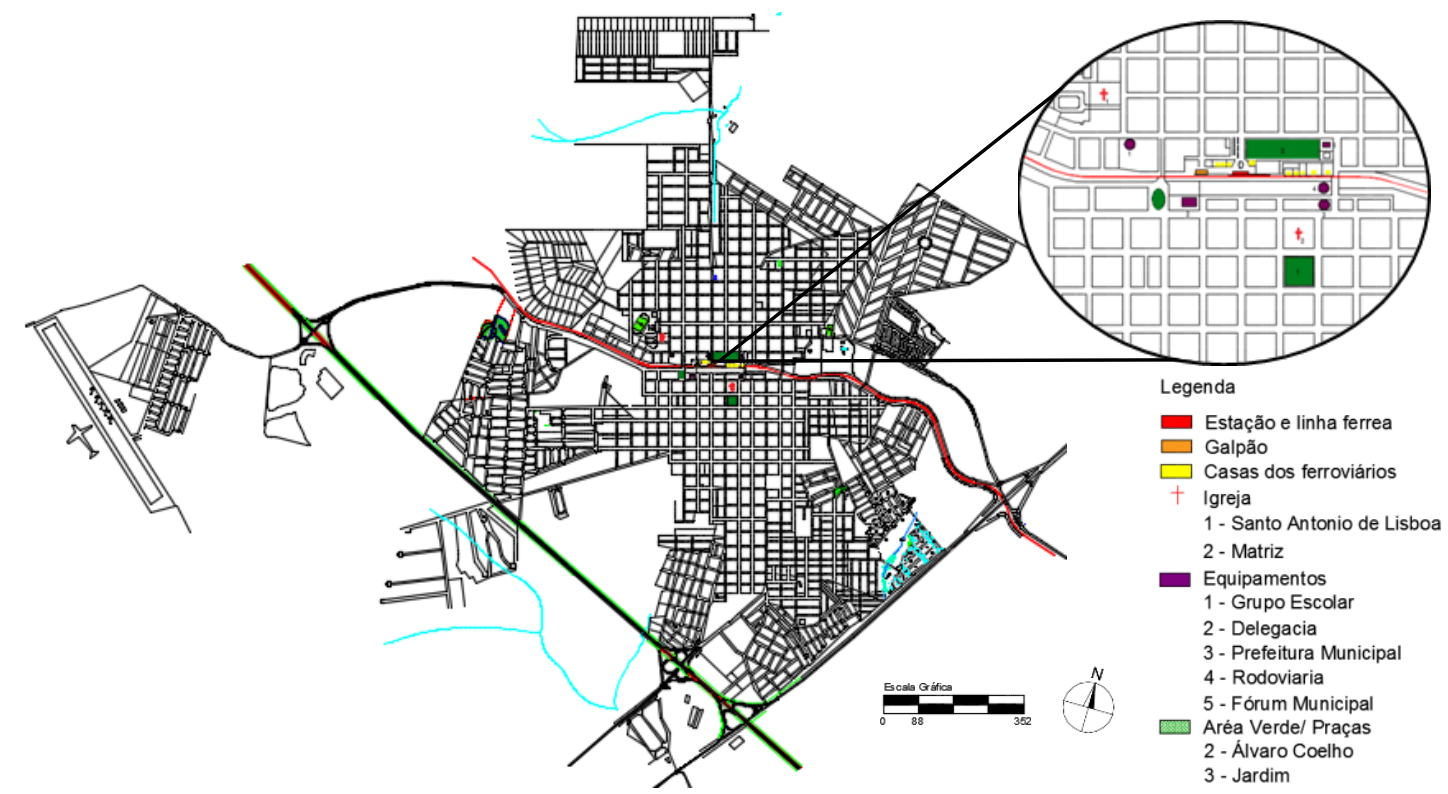

Figura 7. Mapa atual de Presidente Venceslau

Fonte: Prefeitura Municipal de Presidente Venceslau e trabalho de campo, modificado pela autora

As esplanadas de ambas as cidades sofreram alterações. A de Piquerobi foi ocupada por uma pequena praça e por edificações particulares, pelo velório municipal, pela rodoviária e um pequeno parque (figura 8), sendo as casas dos ferroviários demolidas. Em Presidente Venceslau, parte da esplanada foi concedida a prefeitura e essa foi ocupada primeiramente pelo Mercado Municipal e Fórum, e posteriormente esses prédios passaram a ser a Prefeitura Municipal e Câmara Municipal, respectivamente. Também foram construídos a rodoviária da cidade na em parte da esplanada, e a outra parte foi ocupada por estacionamento, além da praça Nicolino Rondó ao lado da Câmara (figura 9). 


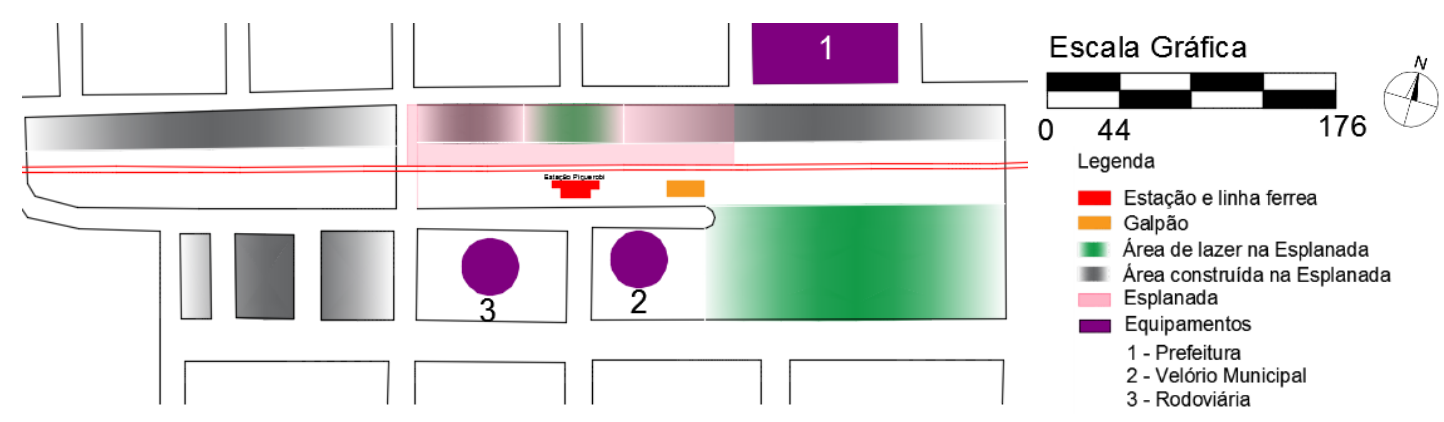

Figura 08. Esboço de ocupação da esplanada de Piquerobi Fonte: Google Maps e trabalho de campo, desenhado pela autora

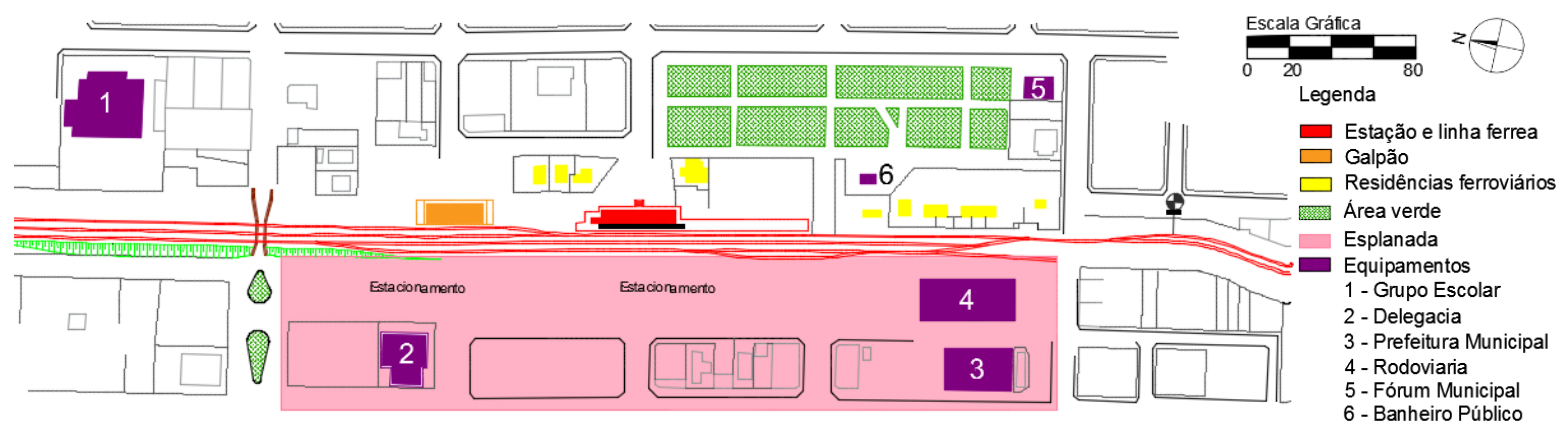

Figura 09. Esboço de ocupação da esplanada de Presidente Venceslau Fonte: Rede Ferroviária Federal AS e trabalho de campo, desenhado pela autora

\section{DISCUSSÃO}

$\mathrm{Na}$ Alta Sorocabana, as estações ferroviárias foram o ponto de origem dos núcleos urbanos, diferente das cidades coloniais, em que a igreja matriz era o local principal da cidade e essa crescia circundando-a. Nas cidades da Alta Sorocabana a estação muitas vezes delimitava as vias principais, e o traçado era feito de forma regular, mesma quantidade de quadras para cada lado. Em Piquerobi e Presidente Venceslau foi observado nos traçados planejados essa regularidade.

As cidades tiveram um fator de destaque, ambos os lados da ferrovia foram ocupados. Contudo, Presidente Venceslau fugiu do padrão, sendo planejada para tal fim, sendo dividida entre lado nobre e "além linha". Com a localização da rodovia, com o passar dos anos, este lado também prosperou e essa divisão ficou imperceptível, sendo que ambos possuem comércio e patrimônio público.

A esplanada de Presidente Venceslau mostrou-se marcante, nela constam os principais edifícios públicos, áreas verdes e também foram preservadas as casas dos ferroviários, grande parte com a estrutura original. Apesar de Presidente Venceslau demostrar uma grande interação entre os dois lados, a esplanada não mostra totalmente essa integração, sendo que boa parte é ocupada por estacionamento. Outro característica interessante é a existência de três igrejas na origem da cidade, sendo que apenas duas delas continuaram existindo até hoje. Esses fatos reforçam a preocupação na manutenção dos patrimônios históricos da cidade.

Diferentemente de Venceslau, Piquerobi não foi planejado para ser ocupado dos dois lados, mas com seu traçado original para o lado oposto da ferrovia. No primeiro núcleo urbano constava a localização da igreja matriz, do grupo escolar e da prefeitura, deles apenas a prefeitura teve sua localização alterada e o antigo prédio passou a ser ocupado pela Secretária Municipal de Educação. Do traçado nada se alterou, e pouco foi expandido, sendo a malha em xadrez fortemente preservada. 
O fato da cidade praticamente não ter sua população alterada, e o que se percebeu foi um decréscimo, dificultou encontrar as memórias da cidade preservadas. As casas dos ferroviários foram demolidas e construído o Velório Municipal e a Estação Rodoviária, do lado oposto foi construída uma pequena praça e o restante tomado por construções de casas particulares, entre eles, encontra-se isolada e preservada a estação ferroviária e o galpão, ambos com uso da prefeitura. Assim, Piquerobi mostrou pouca preservação de seus patrimônios, dificultando reconstruir sua história, sendo apenas o seu traçado o que mais tem ligação com a memória ferroviária.

\section{CONCLUSÃO}

As cidades estudadas apresentaram forte semelhança quanto a forma do traçado (ortogonal) e, apesar de seus planejamentos terem sido diferentes, elas se estruturaram a partir da estação ferroviária, e esse fator manteve-se preservado ao longo do tempo. Por serem cidades pequenas, mesmo com a diferença populacional entre ambas, não ocorreram modificações significativas em seu traçado, sendo marcante na morfologia da cidade.

Presidente Venceslau possui uma forte preservação de seu patrimônio histórico, assim como uma esplanada expressiva, seja pela sua organização espacial, como pela preservação das casas dos ferroviários e da estação. Piquerobi já não possui essa ligação com o patrimônio público tão forte quanto $P$. Venceslau e, apesar de alguns patrimônios estarem preservados, outros encontram-se em um certo grau de degradação. Mesmo assim, em ambas as cidades, os vestígios da ferrovia estão desaparecendo, e a ligação com a mesma praticamente são nulas, seja pela morfologia e análise visual das cidades, seja pela memória de seus habitantes.

\section{REFERÊNCIAS}

ABREU, D. S. Formação histórica de uma cidade pioneira paulista: Presidente Prudente. 6. ed. Presidente Prudente: Faculdade de Filosofia, ciências e letras de Presidente Prudente, 1972.

FRANCISCO, A. M. A EFS como linha de penetração para a ocupação da Alta Sorocabana In: FIORIN, E.; HIRAO. H. (Orgs.). Cidades do Interior Paulista: Patrimônio Urbano e Arquitetônico.1 ed. Jundiaí: Paco Editorial: Cultura Acadêmica, 2015, v.1, p. 81-106.

LAMAS, J. M. R. G. Morfologia urbana e desenho da cidade. 6. ed. Lisboa: Fundação Calouste Gulbenkian, 2011.

MONBEIG, P. Pioneiros e fazendeiros de São Paulo. 3. ed. São Paulo: Polis, 1984.

PANERAI, P. Análise Urbana. Brasília: Universidade de Brasília, 2006. 